\title{
Lise Öğrencilerinin İnternet Bağımlılık Seviyelerinin Genel Akademik Başarıları ve Devamsızlık Durumları ile İlişkisi
}

\author{
Oğuzhan Tekin ${ }^{1}$
}

\section{$\ddot{O} z$}

$\mathrm{Bu}$ çalışmada, lise öğrencilerinin İnternet bağımlılık seviyelerini belirlemek ve bu seviyelerinin öğrencilerin genel akademik başarı ortalamaları ve devamsızlık durumları ile ilişkisini incelemek amaçlanmıştır. İlişkisel tarama modelindeki araştırmanın örneklemini Tokat ili Merkez ilçede amaçsal örneklem ile seçilmiş 220 dokuzuncu ve onuncu sınıf öğrencisi oluşturmaktadır. Çalışmada kullanılan veriler, "İnternet Bağımlılık Ölçeği", "Kişisel Bilgi Formu" ile toplanmış ve öğrencilerin genel akademik not ortalamaları ile devamsızlık durumları Millî Eğitim Bakanlığının e-okul sisteminden alınmıştır. Verilerin analizinde İnternet bağımlılık oranları için frekans, yüzde, aritmetik ortalama ve standart sapma; cinsiyet değişkeni için t-testi, sosyo-ekonomik durum, İnternet kullanım sıklığı ve amacı değişkenleri için ANOVA ve İnternet bağımlılığı seviyelerinin genel akademik başarı ortalamaları ve devamsızlık durumları ile ilişkisini incelemek için de korelasyon analizinden faydalanılmıştır. Verilerin analizinde anlamlılık seviyesi. 05 kabul edilmiştir. Bulgulara göre, lise öğrencilerinin \%25,91'inin İnternet bağımlısı, \%38,18'inin muhtemel bağımlı ve \%34,91'inin bağımlı olmayan profilinde olduğu ortaya konmuştur. Bulgulara göre, lise öğrencilerinin İnternet bağımlılık puanları İnternet erişim süresi ve amacına göre değişmekte; cinsiyetlerine göre farklılaşmamaktadır. Ayrıca araştırmaya katılan öğrencilerin İnternet bağımlılık puanları ile genel akademik başarı ortalamaları arasında negatif yönde ve devamsızlık durumları arasında pozitif yönde anlamlı bir ilişki olduğu ortaya konmuştur.

Anahtar Sözcükler: Akademik başarı, devamsızlık, İnternet bağımlılığı, lise öğrencileri

\begin{abstract}
The aim of this study was to determine the İnternet addiction levels of high school students and investigate the relation between their İnternet addiction levels, grade point average and absenteeism. The sample of the research in the relational survey model consisted of 220 ninth and tenth grade students selected with purposive sampling in the central district of Tokat, Turkey. The data of the study were collected by the "İnternet Addiction Scale", "Personel Information Form". Students' grade point average and absenteeism average were obtained by e-school system. In the analysis of the data; frequency and percentage were used for the İnternet addiction levels of students, t-test was used for gender variable and correlation analysis was used for the relation between the İnternet addiction levels and general academic achievement and absenteeism. The significance level is accepted as .05 in all measurements. Findings of the study revealed that; $25.91 \%$ of the students were İnternet addicts, $38.18 \%$ were probable addicted and $34.91 \%$ were non-addicted, İnternet addiction levels of high school students did not show a statistically significant difference according to their gender. In addition, there was a significant negative correlation between students' İnternet addiction levels and grade point averages and there was a significant positive correlation between İnternet addiction levels and absences.
\end{abstract}

Keywords: Academic achievement, absenteeism, İnternet addiction, high school students

${ }^{1}$ Oğuzhan Tekin, Dr. Öğretmen, MEB, ogztekin@gmail.com 


\section{Giriș}

Dünyada ve Türkiye'de bilgisayar, İnternet ve mobil teknolojilerin kullanımı oransal olarak giderek artma eğilimindedir. Türkiye İstatistik Kurumu (TÜİK) verilerine göre, 2007 yılında \%18,9 olan hane halkı İnternet sahibi olma oranlarının 2012 yılında \%47,2'ye, 2015 yılında \%55,9'a, 2016 yılında \%76'ya, 2017 yılında \%80,7'ye ve 2018 yılında ise \%83,4'e yükseldiği görülmektedir (TÜİK, 2018). Türkiye'de İnternet ve mobil araçların kullanımının giderek yaygınlaşmasının ve kullanım oranlarının artmasının nedenleri arasında, Türkiye' nin gelişmekte olan bir ülke olmasının, genç ve ergen nüfusunun fazla olmasının etkili olduğu belirtilmektedir (Fuat, 2013). Nitekim araştırmalar, Türkiye'de İnternet kullanmaya başlama yaşının ortalama 9 olduğunu, bunun giderek düştüğünü ve yaş gruplarına göre İnternet kullanım oranlarında \%82 ile en yüksek oranın 15-24 yaş grubuna ait olduğunu göstermektedir (TÜIK, 2018).

Teknolojinin insan hayatına getirdiği sayısız faydalar vardır. Dünyada ve Türkiye'de kullanım oranları gitgide artan İnternet, etkili bir iletişim ve bilgi paylaşım aracı olup iş yaşamı ve günlük yaşamda işleri önemli ölçüde kolaylaştırmaktadır. İnternet'in insan yaşamına sunmuş olduğu en önemli fırsat, bilgi edinme ve iletiminde getirmiş olduğu fırsat eşitliğidir. İnternet'in sunduğu bu fırsat ile büyük yatırımlar gerektiren geleneksel iletişim yöntemleri değişmiş, İnternet kullanıcıları bilgi ve fikirlerini tüm dünya ile kolayca ve maliyetsiz olarak paylaşmaya başlamışlardır. İnternet, iletişimden bilgi paylaşımına, habercilikten medya okuryazarlığına, tanıtım faaliyetlerinden gezi ve tatile, kamu hizmetlerinden bankacılık ve alışverişe, eğlenceden sosyal ilişkiler ve kültürler arası etkileşime, sağlık hizmetlerinden eğitime ve günlük yaşamı ilgilendiren pek çok alanda olumlu getiriler ve yenilikleri insanların yaşamına kolaylık olarak sunmaktadır (Turanalp, 2016).

Sunduğu kolaylık ve faydalarının yanında İnternet, kullanımının herkese denetimsiz olarak açık olması, bilgi ayrımı olmaması, aşıı bilgi yüklemesi, bilgi güvensizliği, bilişim suçlarına mahal vermesi ve İnternet bağımlılı̆̆ gibi ciddi problemlere de sebep olabilmektedir (Kim ve Kim, 2002). İnternet ve mobil teknolojilerin toplum içerisinde en çok gençler ve ergenler arasında kabul gördüğü ve kullanımının yaygın olduğu düşünüldüğünde bu problemlerin en çok genç ve ergen yaş grubunu etkilediği söylenebilir. Çünkü özdenetim bakımından daha zayıf ve dış etkenlerden etkilenmeye daha yatkın olan genç ve ergenlerin İnternetin faydaları kadar zararlarına da maruz kalacağı belirtilmektedir (Ceyhan ve Ceyhan, 2014). İnternet'in sağlamış olduğu sınırsız bilgi, aynı zamanda yanlış bilgilere ulaşma, bilgi dezenformasyonu ve bilginin değeri sorununu da beraberinde getirmektedir. Çünkü İnternet ortamında bilgi iletimi çok hızlı gerçekleşmekte ve bilgiye erişimde çoğu zaman kaynakların doğruluğuna ve birinci kaynak olup olmadığına dikkat edilmemektedir. Bu şekilde elde edilen bilgiler doğrulanmadan genç ve ergenler tarafından kullanılmakta ve paylaşılmaktadır. Bu durum doğru bilgilerin edinilmesi ve paylaşılması için olumlu bir durum olsa da yanlış bilgilerin edinilip paylaşılması 
bakımından olumsuz bir durumu ortaya çıkarmaktadır (Odabaşığlu ve arkadaşları, 2007). Bununla birlikte kullanımının yaygınlaşması yardımıyla İnternet kötü niyetli insanlar için vazgeçilmez bir suiistimal ortamı hâline gelmiştir. İnternet aracılığıyla işlenen suçlar arasında, siber dolandırıcılık, siber zorbalık, kötü propaganda ve yandaş temini, zararlı bilgi paylaşımı sayılabilir. Bunun yanında genç ve ergenler için suç işleme yollarını öğrenme bakımından denetimsiz olması ve suç işlemeye teşvik edici olması da önemli bir olumsuzluk olarak görülmektedir (Değirmenci, 2002).

İnternet'in müstehcen içerikleri kontrolsüz olarak sunması genç ve ergenler için sorun teşkil edebilir. Çünkü bu yaş grubunun en belirgin özelliklerinde biri biyolojik gelişimlerinin devam etmesi ve bu konuda merak duygularının üst seviyede olmasıdır (Kılıç, 2018). Sağlıklı bir şekilde yönlendirilip bilinçlendirilmezlerse bu alandaki meraklarını farklı kanallardan giderme ihtiyacı hissedebilirler. İnternet, yetişkin içeriklere denetimsiz olarak erişebilme olanağı sağladığından genç ve ergenler için bu ihtiyaçlarını gidermede başvurdukları en yaygın yollardan biridir (Çelen, Çelik ve Seferoğlu, 2011). Araştırmalar İnternet ortamında milyonlarca yetişkin içerikli site olduğunu ve İnternet'te yapılan aramaların neredeyse yarısının cinsel içerikli olduğunu ortaya koymaktadır (Karaca ve Beyaznar, 2010). Ayrıca İnternet'te kişisel mahremiyet ihlal edilebileceğinden ve siber zorbalık tehdidi olabileceğinden İnternet genç ve ergenler için zararlı olabilmektedir (Cao ve Lin, 2015).

Bilgi ve iletişim teknolojileri kullanımı bilgiye ulaşmanın etkili yollarından biri olmakla birlikte gençler ve ergenler için bir eğlence ve boş vakit geçirme aracı olarak da görülmektedir. Yapılan araştırmalar genç ve ergenlerin İnternet'i daha çok sosyal medyayı takip etmek ve çevrimiçi oyunlar oynamak amacıyla kullandıklarını göstermektedir (Günel, Turhal ve İmal, 2011). Bu noktada iki temel sorun dikkat çekmektedir. Birincisi, zaman yönetimi ve zamanı verimli kullanma konusunda yaşanan sorunlar, ikincisi ve belki de en önemlisi, İnternet başında geçirilen çok fazla zamandan dolayı ortaya çıabilecek olan bağımlılık sorunudur (Adiele ve Olatokun, 2014).

Bağımlılık genel olarak Egger ve Rauterberg (1996) tarafından, bireyin kullanmakta olduğu madde veya gerçekleştirdiği bir davranış üzerindeki bireysel yönetimini kaybetmesi ve onsuz normal yaşantısını devam ettirememeye başlaması olarak tanımlanmaktadır. Bağımlı birey kendi iradesi dışında söz konusu davranışı veya madde kullanımını sergilemeye devam etmektedir. Bununla birlikte bağımlılık tanısı konulan bireyler, bağımlı olduğu maddeyi veya davranışı hayatının merkezine koyacak ve yapmak zorunda olduğu görev ve sorumlulukları ihmal ederek enerjisinin ve zamanının büyük bölümünü bağımlı olduğu madde veya davranış için harcayacaktır (Young, 1998). Bu bilgilere göre bağımlılığın madde ve davranış olmak üzere iki temel türü olduğu söylenebilir.

Madde bağımlılığı daha çok alkol, sigara, uyuşturucu gibi fiziksel bir madde kullanımı ve bu kullanım üzerindeki kontrol ve iradenin kaybolması olarak tanımlanmaktadır (Waldron ve Turner, 2008). Davranışsal bağımlılıklar ise temeli fiziksel bir maddeye dayanmayan, yemek, oyun, seks, 
alışveriş, televizyon, bilgisayar, İnternet gibi davranışlar üzerinde kontrol ve iradenin kaybı olarak tanımlanmaktadır (Kim ve Kim, 2002). Her iki durumda da bağımlılık tanısı konulabilmesi için bireyin davranış ya da eylemi kontrol edememesi, olumsuz sonuçlarının farkında olmasına rağmen davranış ya da eylemi gerçekleştirmeye devam etmesi ve denemesine rağmen bırakamaması gerekmektedir (Günüç ve Kayri, 2010).

Davranış tabanlı bağımlılık; yeme, oyun, kumar gibi bağımlılıkların yanında, makine - insan etkileşimi sonucu ortaya çıkan teknoloji bağımlılıklarını da kapsamaktadır. Teknoloji bağımlıklarına; televizyon, cep telefonu, medya, bilgisayar ve İnternet bağımlılığı örnek olarak verilebilir. Bu tür bağımlılıklarda bağımlı birey pasif ya da aktif-etkileşimli rolde olabilmektedir. Mesela; TV bağımlılığında kişi pasif izleyiciyken, bilgisayar ve İnternet bağımlılıklarında birey makineyle ya da diğer bireylerle etkileşim içerisinde dolayısıyla aktif olabilmektedir (Griffiths, 1999). Günümüzde, özellikle gelişen teknoloji ile birlikte İnternet'in yaşamın içerisine girmesi, kullanım oranının giderek yükselmesi ve kullanıcılarına aktif ve etkileşim içinde oldukları bir ortam sağlaması sebebiyle bağımlılık kapsamında oluşturduğu risklerin diğer teknoloji araçlarına göre daha yüksek olduğu söylenebilir. Uluslararası alanyazında, "İnternet dependency (İnternet bağımlılı̆̆ı)", "pathological İnternet use (patolojik İnternet kullanımı)”, "excessive İnternet use (aşırı İnternet kullanımı)”, “İnternet abuse (İnternet istismarı)" ve "İnternet addiction disorder (düzensiz İnternet kulanımı)" gibi kavramlar İnternet kullanımı ile ilgili problemli davranış biçimlerini betimlemek için yaygın olarak kullanılmaktadır (Ceyhan ve Ceyhan, 2014). Ulusal alanyazında ise bu kavramın daha çok İnternet bağımlılığı şeklinde kabul edildiği görünmektedir. Bu çalışmada problemli İnternet kullanımı ile ilgili "İnternet bağımlılığı" teriminin kullanılması benimsenmiştir.

Olumsuz bir durumu ifade eden İnternet bağımlılığı, Young (1998) tarafından İnternet kullanımı amacıyla bilgisayar başında çok uzun süreler geçirme ve bu kullanma dürtüsü üzerindeki öz yönetimini yitirme şeklinde tanımlanmıştır. Bir başka deyişle bireyin İnternet bağımlısı olarak nitelenmesindeki en büyük etkenler, İnternet başında diğer işlerini aksatacak kadar uzun zaman geçirmesi ve bu durumu kontrol altına alamamasıdır. Young'a (1998) göre İnternet bağımlılığı sonucu ortaya çıabilecek problemler akademik, ailevi ve sosyal problemler, ekonomik, iş ve fizyolojik problemler olmak üzere beş kategoride toplanmıştır. Araştırmalara göre, İnternet bağımlısı olarak nitelenen bireylerde; işyeri ve okul performanslarının olumsuz etkilenmesi, uyku bozukluğu, İnternetsiz bir yaşamın sıkıcı ve anlamsız gelmesi, yoğun irade kaybı, İnternet'ten yoksun kaldığında aşırı sinirlilik ve anksiyete hâli gibi psikolojik belirtilerin yanında; İnternet başında uzun süre kalmaktan bir takım fizyolojik belirtiler de gözlenmektedir (Nalwa ve Anand, 2003).

Bununla birlikte son zamanlarda İnternet veya teknoloji bağımlılığı tıp dünyasında patalojik ve psikolojik bir rahatsızlık olarak da rapor edilmektedir (Arısoy, 2009). Örneğin; İnternet kullanım 
süresine bağlı olarak çocuk ve gençlerde bilişsel süreçlerin olumsuz etkilendiği, duygusal duyarlılı̆̆ın azaldığı ve genel sağlık düzeyinin olumsuz etkilendiği; sosyal gelişimlerinin yavaşladığı, öz güven kaybı yaşadıkları ve saldırganlık davranışlarının arttığı tespit edilmiştir (Arısoy, 2009). Aynı zamanda problemli İnternet kullanımının takıntı, kaygı, depresyon, düşmanca, fobik ve paranoid gibi patalojik düşüncelerin artmasına yol açtığı belirtilmektedir (Odabaşığlu ve arkadaşları, 2007). Belirtilen araştırma bulgularına göre, problemli İnternet kullanımı davranışı sergileyen genç ve ergenlerin gitgide yalnızlaştığı ve yüz yüze ilişki kurmakta zorlandıkları görülmektedir. Türkiye'de İnternet kullanım oranları dikkate alındığında, problemli İnternet kullanımı davranışı sonucu gelişmesi muhtemel olan psikolojik ve fizyolojik problemlerin en çok genç ve ergenleri etkileyebileceği söylenebilir.

Gençler ve ergenler arasında İnternet kullanım oranlarının artmasının önemli nedenlerinden biri de sürekli gelişme ve üye profilini artırma eğiliminde olan Facebook, Twitter, İnstagram gibi sosyal ağlardır (Gülbahar, Kalelioğlu ve Madran, 2010). Bu ağlarda geçirilen süre kontrol altına alınmadığında bireyler üzerinde olumsuz bir etki yaratması ve bağımlılı̆̆ı tetiklemesi olasıdır. Araştırmalara göre 25 yaş altındaki gençler, sosyal ağları takip etmek uğruna uykularını terk edebildiklerini, sosyal ve ailevi ilişkilerini ihmal edebildiklerini, öğrenim çağında olanlar da akademik ödev ve sorumluluklarını aksatabildiklerini belirtmişlerdir (Ofcom, 2008). Dolayısıyla bu ağları en çok kullanan kesimin gençler olduğu düşünüldüğünde (Retrevo, 2010), henüz akademik hayatlarının ve geleceğe dönük kariyer planlamalarının başlarında olan bu bireyler için çok değerli olan zamanın etkisiz bir şekilde kullanılması, onların ilerdeki sosyal ve akademik yaşamlarında sorunlar yaratabilir. Özellikle lise öğrencileri, içinde bulundukları ergenlik döneminde yaşanan kimlik kargaşası, duyguları uç boyutlarda yaşama eğilimi, sosyal uyum problemleri ve meslek seçimi ile girdiği sınavlardaki yüksek rekabet ortamının oluşturduğu gerilim gibi sorunlarla karşı karşıya gelebilmektedirler (Aydın, 2005). Öğrenciler bu ve benzeri sorunlarla başa çıkabilmek için problemli İnternet kullanımını bir strateji olarak kullanabilirler.

Ulusal ve uluslararası boyutta İnternet kullanım hızının artmasıyla birlikte İnternet bağımlılı̆̆ı kavramı birçok araştırmaya konu olmuştur. Yapılan çalışmalarda İnternet bağımlılığı; kişilik özellikleri (Batıgün ve Kılıç, 2011; Ekşi, 2012; Shepherd, ve Edelmann, 2005), yalnızlık (Esen ve Siyez 2011; Mitchell, 2000), saldırganlık ve akran baskısı (Satan, 2013; Yükselgün, 2008) ve siber zorbalık (Özdemir ve Akar, 2011; Ybarra, 2004) gibi kavramlarla ilişkilendirilmiştir. Bazı çalışmalarda ise İnternet bağımlılığının, bireylerin İnternet'i kullanma amaçları, kullanım sıklıkları ve tutumları ile ilişkileri incelenmiştir (Morsünbül, 2014). Young ve Case (2004), ergenlerin İnternet'te geçirdikleri fazla zamandan dolayı aile ve arkadaş ilişkilerinin zayıfladığını ve derslerine gerekli ilgiyi göstermediklerini ifade etmişlerdir. Işık (2007), 563 üniversite öğrencisi ile gerçekleştirdiği çalışmasında İnternet kullanım süresi ve sıklığının giderek arttığını belirtmiştir. Bicen ve Çavuş (2010), öğrencilerin sosyal medya kullanım durumlarını 
belirlemeye yönelik araştırmalarında ortaöğretim öğrencilerinin \%94'ünün bir sosyal ağa üye olduğunu ve düzenli olarak takip ettiğini ve bu durumun öğrencilerin sosyal beceri ve akademik ödev de sorumluluklarını aksatmalarına neden olduğunu ifade etmişlerdir. Britanya'da 371 üniversite öğrencisi ile yürütülen bir çalışmada katılımcıların \%18,3'ünün İnternet bağımlısı olduğu ve bağımlı bireylerin sosyal ilişkiler ve akademik başarı yönünden diğerlerine göre daha olumsuz durum sergiledikleri belirtilmiştir (Niemz, Griffiths ve Banyard, 2005).

İnternet bağımlılığının birçok araştırmacı ve psikolog tarafından önemli bir patolojik rahatsızlık olarak görüldüğü, bireylerin sosyal ve akademik yaşamını olumsuz etkilediği, tedavi edilmesi gerektiği ve bağımlılık riskinin İnternet'i en çok kullanan yaş grubu olan genç ve ergenlerde daha yüksek olduğu bilinmektedir (Arısoy, 2009). Dolayısıyla İnternet bağımlılığı kavramı Türkiye Büyük Millet Meclisi (TBMM) tarafından da en üst düzeyde görülmüş ve 2012 yılında kurulan meclis araştırma komisyonunun raporunda, İnternet'in gençler ve çocuklar üzerindeki etkilerinden söz edilirken birçok olumsuz etkisinin yanı sıra İnternet bağımlılığına özellikle dikkat çekilmiştir. Ayrıca bu raporda, çocuk ve gençlerin teknoloji bağımlılı̆̆ı ve sorunlu İnternet kullanımının erken dönemde aileler veya öğretmenler tarafından fark edilebilmesi amacıyla çalışmalar yapılması (s.984), İnternet'in sorunlu kullanımına ilişkin ulusal düzeyde yürütülen araştırmaların yaygınlaştırılması (s.985) önerilmiştir (TBMM, 2012). Türkiye'de ortaöğretim çağında olan bireylerin akademik başarılarının ve zaman yönetimlerinin gelecek planlamalarına doğrudan etki ettiği düşünüldüğünde, bu bireylerin İnternet kullanım alışkanlıklarının ve bağımlılık düzeylerinin tespit edilmesinin oldukça yararlı olacağı düşünülmektedir. Bu sayede ailelere, okul yöneticilerine ve okullardaki rehberlik servislerine gerekli önlemlerin alınması adına öneriler sunulabilir. Bu kapsamda, İnternet veya teknoloji bağımlılığı ile lise öğrencilerinin akademik başarıları ve derse devam durumları arasındaki ilişkinin araştııılmasının önemli olduğu ve ilgili alanyazına katkı sağlayacağı düşünülmektedir.

Bu araştırmada, lise öğrencilerinin İnternet bağımlılık seviyelerinin belirlenmesi ve bu seviyelerin öğrencilerin genel akademik başarıları ve devamsızlık durumları ile ilişkisinin incelenmesi amaçlanmıştır. Bu amaçla çalışmaya yön veren araştırma soruları aşağıdaki gibidir:

1. İnternet'e yönelik bağımlılık gösterme eğilimleri nasıldır?

2. İnternet bağımlılık seviyeleri öğrencilerin demografik özelliklerine göre farklılaşmakta mıdır?

3. İnternet bağımlılık seviyelerinin genel akademik başarı ortalamaları ve devamsızlık durumları ile ilişkisi nasıldır? 


\section{Yöntem}

\section{Araştırma Modeli}

Lise öğrencilerinin İnternet bağımlılık düzeylerini ve bu düzeylerin öğrencilerin genel akademik başarı ortalamaları ve devamsızlık durumları ile ilişkisini incelemeyi amaçlayan mevcut çalışma ilişkisel tarama modelindedir. Tarama modeli, geçmişte gerçekleşmiş veya hâlen yaşanmaya devam eden bir olguyu, olduğu gibi derinlemesine betimlemeyi amaçlayan bir araştırma yaklaşımıdır (Karasar, 2000).

\section{Çalışma Grubu}

Araştırmanın katılımcı grubu, Tokat ili Merkez ilçede Millî Eğitim Bakanlığına bağlı bir devlet lisesinde öğrenim görmekte olan ve amaçsal örnekleme tekniği ile seçilen toplam 220 dokuzuncu ve onuncu sınıf öğrencisinden oluşmaktadır. Öğrencilerin 112'si kız $(\% 50,9), 108$ 'i $(\% 49,1)$ erkektir. Çalışma grubunun 132'si (\%60) 9'uncu sınıf, 88'i (\%40) 10'uncu sinıf öğrencisidir. Araştırmada çalışma grubu olarak dokuz ve onuncu sınıf öğrencilerinin seçilmesini temel gerekçesi, bu yaş grubunda İnternet kullanım oranlarının diğer ergenlere göre belirgin şekilde yüksek olmasıdır (Karaca, 2007; Kurtaran, 2008; Odabaşıoğlu ve arkadaşları, 2007). Ayrıca, bu yaş grubu öğrencileri için kariyer planlaması ve sınavlara hazırlık bakımından zaman yönetimi ve akademik başarının önemi oldukça fazladır. Katılımcıların özellikleri Tablo 1'de gösterilmiştir.

Tablo1. Katılımcıların Özellikleri

\begin{tabular}{llcc}
\hline Değişkenler & & $f$ & $\mathbf{\%}$ \\
\hline \multirow{2}{*}{ Cinsiyet } & Kız & 112 & 50.9 \\
& Erkek & 108 & 49.1 \\
\hline \multirow{2}{*}{ Sınıf } & 9. Sınıf & 132 & 60 \\
& 10. Sınıf & 88 & 40 \\
\hline \multirow{3}{*}{ Algılanan Sosyo-ekonomik Durumu } & Zayıf & 7 & 3.2 \\
& Orta & 186 & 84.5 \\
& İyi & 27 & 12.3 \\
\hline \multirow{3}{*}{ İnternet Kullanma Sıklığı } & Hiç & 0 & 0 \\
& Ayda birkaç defa & 16 & 7.3 \\
& Haftada birkaç defa & 56 & 25.5 \\
& Her gün & 148 & 67.2 \\
\hline \multirow{3}{*}{ İnternet Kullanım Amacı } & Araştırma-bilgi edinme & 44 & 20 \\
& Eğlence & 99 & 45 \\
& İletişim & 76 & 34.5 \\
& Alışveriş & 1 & .5 \\
& Kullanmıyorum & 0 & 0 \\
\hline
\end{tabular}

Tablo 1'de görüleceği gibi, öğrencilerin ekonomik durumları zayıf $n=7(\% 3,2)$, orta $n=186(\% 84,5)$ ve iyi $\mathrm{n}=27$ (\%12,3) şeklindedir. Öğrencilerin n=16's1 (\%7,3) ayda birkaç defa, $n=56(\% 25,5)$ haftada birkaç defa ve $n=148(\% 67,2)$ her gün İnternet erişimine sahiptir. Öğrencilerin İnternet'i daha çok kullanım 
amaçları $n=44$ (\%20) araştırma ve bilgi edinme, $n=99(\% 45)$ oyun eğlence, $n=76(\% 34,5)$ iletişim, n=1 $(\% 0,5)$ şeklindedir ve İnternet kullanmayan öğrenci bulunmamaktadır.

\section{Veri Toplama Araçları}

Araştırmada, lise öğrencilerinin problemli İnternet kullanım düzeylerini belirlemek amacıyla, Young (1998) tarafından geliştirilen ve Bayraktar (2001) tarafından Türkçe uyarlaması yapılan 20 maddelik “İnternet Bağımlılık Ölçeği” kullanılmıştır. 5'li likert tipinde oluşan ölçeğin puanlanmasında 1=“Hiçbir zaman” ve 5=“Her zaman” aralığındaki seçenekler kullanılmaktadır. Ölçekten alınan puan yükseldikçe bağımlılık riski de yükselmektedir. Ölçekten elde edilecek puanlara göre öğrenciler "bağımlı" (70-100 aralığı), "muhtemel bağımlı" (40-69 aralığı) ve “bağımlı olmayan" (39 puan ve altı) olarak nitelendirilmiştir (Young, 1998). Orijinal ölçeğin iç tutarlık güvenirlik katsayısı 85 (Young, 1998), çeviri ölçeğin iç tutarlık güvenirlik katsayısı .91 (Bayraktar, 2001), mevcut çalışma özelinde tüm ölçümler için bu değer .86 olarak hesaplanmıştır. Bu sonuçlar ölçekten elde edilen verilerin yüksek güvenirlikte olduğunu göstermektedir (Büyüköztürk, 2015).

Öğrencilerin kişisel özelliklerini belirlemek amacıyla araştırmacı tarafından "Kişisel Bilgi Formu" geliştirilmiştir. Bu formda cinsiyet, İnternet kullanım sıklı̆̆ı, İnternet erişim durumu ve kullanım amaçları gibi demografik bilgilerin toplanması amaçlanmıştır. Öğrencilerin genel akademik başarı ortalamaları ve devamsızlık durumları, Millî Eğitim Bakanlığının okullar için geliştirdiği otomasyon sistemi olan e-okul (elektronik okul) kullanılarak elde edilmiştir.

\section{İşlem}

Çalışmada veri toplamak için Tokat İl Millî Eğitim Müdürlüğünden gerekli izinler alınmıştır. Çalışma grubuna “İnternet Bağımlılık Ölçeği” ve "Kişisel Bilgi Formu” araştırmacı tarafından uygulanmıştır. Uygulamadan önce, araştırmacı tarafından katılımcılar, yürütülen çalışma, ölçek ve bilgi formu hakkında kısaca bilgilendirilerek anketlere doğru ve samimi yanıtlar verilmesi konusunda cesaretlendirilmiştir.

Araştırmanın verileri, bilgisayar ortamında SPSS programı kullanılarak analiz edilmiştir. Analizler sırasında parametrik testler uygulanmasının ön koşullarından biri kullanılan verilerin normal dağılmasıdır (Büyüköztürk, 2015). Bu çalışmada verilerin normal dağılımını test etmek amacıyla öğrencilerin İnternet bağımlılık ölçeği puanlarının çarpıklık basıklık değerlerine bakılmıştır. Çarpıklık basıklık değerlerinin +1 ve -1 aralığında olduğu dolayısıyla verilerin normal dağılım gösterdiği görülmüş bu nedenle analizlerde parametrik testler kullanılmasına karar verilmiştir. Verilerin analizinde; yaş, cinsiyet, İnternet kullanım sıklığı değişkenleri için frekans, yüzde, aritmetik ortalama, standart sapma gibi betimsel istatistiklerden faydalanılmıştır. Ayrıca, İnternet bağımlılık seviyelerinin cinsiyet değişkenine göre incelenmesi için bağımsız gruplar t-testi, İnternet kullanım amacı ve sıklığı 
değişkenleri için ANOVA ve bağımlı ve bağımsız değişkenlerin ilişkilerini incelemek için de korelasyon analizi gibi yordamsal istatistiklerden de faydalanılmıştır.

\section{Bulgular}

\section{Birinci Alt Probleme İlişkin Bulgular}

Öğrencilerin İnternet'e yönelik bağımlılık gösterme eğilimlerini incelemek amacıyla İnternet bağımlılık ölçeğinden alınan puanlar analiz edilmiştir. Ölçekten elde edilen $X=51.65$, maksimum puan 96, minimum puan 20 ve SS=19.48 olarak hesaplanmıştır. Lise öğrencilerinin İnternet bağımlılık profilleri Tablo 2' de sunulmuştur.

Tablo 2. Lise Öğrencilerinin İnternet Bağımlılık Profilleri

\begin{tabular}{lll}
\hline & $f$ & \% \\
\hline Bağımlı Değil & 79 & 36 \\
Muhtemel Bağımlı & 84 & 38 \\
Bağımlı & 57 & 26 \\
Toplam & 220 & 100 \\
\hline
\end{tabular}

Tablo 2'ye göre araştırmaya katılan lise öğrencilerinin 79'u (\%36) “Bağımlı Değil”, 84'ü (\%38) “Muhtemel Bağımlı” ve 57'si (\%26) “İnternet Bağımlısı” profilindedir.

\section{İkinci Alt Probleme İlişkin Bulgular}

Öğrencilerin İnternet bağımlılık ölçeği puanlarının cinsiyetlerine göre değişip değişmediğini incelemek amacıyla puan ortalamalarına bağımsız örneklemler t-testi gerçekleştirilmiş ve sonuçlar Tablo 3'te sunulmuştur.

Tablo 3. Öğrencilerin Cinsiyetlerine Göre İnternet Bağımlılığı Seviyeleri

\begin{tabular}{llcccccc}
\hline Ölçek & Gruplar & $N$ & $X^{-}$ & $S S$ & $t$ & $s d$ & $p$ \\
\hline İnternet Bağımlılı̆̆1 & Kız & 112 & 51.36 & 20.57 & & & \\
Ölçeği & Erkek & 108 & 51.65 & 18.36 & .223 & 218 & .824 \\
${ }^{*} p<.05$ & & & & & & &
\end{tabular}

Tablo 3'e göre kız öğrencilerin puanlarının $X=51.36$, SS=20.57 ve erkek öğrencilerin puanlarının $X=51.96, \mathrm{SS}=18.36$ olduğu görülmektedir. Gerçekleştirilen t-testi sonucuna göre kız ve erkek öğrencilerin İnternet bağımlılık puan ortalamaları arasında istatistiksel olarak anlamlı düzeyde farklılık bulunmamıştır [t(218)=.-223, p>.05]. Öğrencilerin ailelerinin sosyo-ekonomik durumları ve İnternet bağımlılık puanları ile ilgili betimsel istatistikler Tablo 4'te sunulmuştur. 
Tablo 4. Öğrencilerin Sosyo-ekonomik Durumlarına Göre İnternet Bağımlılık Puanları

\begin{tabular}{ccccc}
\hline & Ekonomik Durum & $\boldsymbol{N}$ & $\boldsymbol{X}$ & SS \\
\hline İnternet Bağımlılığ & Zayıf & 7 & 39.43 & 19.24 \\
& Orta & 186 & 51.74 & 19.63 \\
& İyi & 27 & 54.15 & 17.93 \\
\hline
\end{tabular}

Tablo 4'te görüldüğü gibi ekonomik durumları "zayıf" düzeyde 7 öğrenci ( $X=39.43$, SS=19.24), “orta" düzeyde 186 öğrenci ( $X=51.74, S S=19.63)$ ve "iyi" düzeyde 27 öğrenci ( $X=54.15, S S=17.93)$ bulunmaktadır. Öğrencilerin İnternet bağımlılık seviyelerinin ekonomik durumlarına göre değişip değişmediğini incelemek amacıyla ANOVA analizi gerçekleştirilmiş ve sonuçlar Tablo 5'te gösterilmiştir.

Tablo 5. Sosyo-ekonomik Duruma Göre ANOVA Analizi Sonuçları

\begin{tabular}{lccccc}
\hline & $\begin{array}{c}\text { Kareler } \\
\text { Toplamı }\end{array}$ & $s d$ & $\begin{array}{c}\text { Kareler } \\
\text { Ortalaması }\end{array}$ & $\boldsymbol{F}$ & $p$ \\
\hline Gruplar Arası & 1215.61 & 2 & 607.81 & & \\
Gruplar İçi & 81848.74 & 217 & 377.18 & 1.611 & .202 \\
Toplam & 83068.35 & 219 & & & \\
\hline${ }^{*} p<0.5$
\end{tabular}

Tablo 5 incelendiğinde araştırmaya katılan öğrencilerin İnternet bağımlılık puanlarının ailelerinin sosyo-ekonomik durumlarına göre farklılaşmadığı görülmektedir [F(2,217)=1.611), p>.05]. Öğrencilerin kullanım sıklığına göre İnternet bağımlılık puanları Tablo 6' da sunulmuştur.

Tablo 6. Öğrencilerin Kullanım Sıklığına Göre ve İnternet Bağımlılık Puanları

\begin{tabular}{llccc}
\hline & $\begin{array}{l}\text { İnternet Kullanım } \\
\text { Sıklı̆̆ı }\end{array}$ & $N$ & $X$ & SS \\
\hline \multirow{3}{*}{ İnternet Bağımlılığı } & Ayda Birkaç Defa & 16 & 30.75 & 5.97 \\
& Haftada Birkaç Defa & 56 & 41.14 & 14.24 \\
& Her gün & 148 & 57.88 & 18.89 \\
\hline
\end{tabular}

Tablo 6'da görüldüğü gibi öğrencilerin 16'sı “Ayda birkaç defa” ( $X=30.75, S S=5.97), 56$ 's1 “Haftada birkaç defa” ( $X==41.14$, SS=14.24), 148'i “Her gün” ( $X=57.88$, SS=18.89) İnternet kullanmakta ve İnternet kullanmayan öğrenci bulunmamaktadır. Öğrencilerin İnternet bağımlılık puanlarının kullanım sıklığına göre değişimini incelemek amacıyla ortalama puanlarına ANOVA gerçekleştirilmiş ve sonuçlar Tablo 7'de gösterilmiştir.

Tablo 7. Kullanım Sıklığına Göre İnternet Bağımlılık Puanları ANOVA Sonuçları

\begin{tabular}{llllll}
\hline & $\begin{array}{l}\text { Kareler } \\
\text { Toplamı }\end{array}$ & $s d$ & $\begin{array}{l}\text { Kareler } \\
\text { Ortalamasi }\end{array}$ & F & $p$ \\
\hline Gruplar Arası & 18912.68 & 2 & 9456.34 & & \\
Gruplar İçi & 64151.67 & 217 & 295.63 & 31.99 & $.000^{*}$ \\
Toplam & 83064.35 & 219 & & & \\
${ }^{*} p<.05$ & & & & &
\end{tabular}


Tablo 7'ye göre lise öğrencilerinin İnternet bağımlılık puan ortalamalarının kullanım sıklığı değişkenine göre farklılaşttğı görülmektedir $[F(2,217)=31.99$, p<.05]. Farkın kaynağını belirlemek ve çoklu karşılaştırmalar yapmak amacıyla Scheffe testi uygulanmış ve sonuçlar Tablo 8' de sunulmuştur.

Tablo 8. Öğrencilerin İnternet Kullanım Sıklığına Göre Bağımlılık Seviyeleri Scheffe Testi

\begin{tabular}{|c|c|c|c|c|c|}
\hline & $\begin{array}{l}\text { İnternet Kullanım } \\
\text { Sıklığı }\end{array}$ & Karşılaştırmalar & $\begin{array}{l}\text { Ortalamalar } \\
\text { Farkı }\end{array}$ & $S H$ & $p$ \\
\hline \multirow{6}{*}{$\begin{array}{l}\text { İnternet } \\
\text { Bağımlılık } \\
\text { Puanları }\end{array}$} & \multirow{2}{*}{ Ayda Birkaç Defa } & Haftada Birkaç Defa & -10.39 & 4.87 & .105 \\
\hline & & Hergün & -27.13 & 4.52 & $.000^{*}$ \\
\hline & \multirow{2}{*}{ Haftada Birkaç Defa } & Ayda Birkaç Defa & 10.39 & 4,87 & .105 \\
\hline & & Hergün & -16.73 & 2.69 & $.000^{*}$ \\
\hline & \multirow{2}{*}{ Hergün } & Ayda Birkaç Defa & 27.13 & 4.52 & $.000^{*}$ \\
\hline & & Haftada Birkaç Defa & 16.73 & 2.69 & $.000^{*}$ \\
\hline
\end{tabular}

${ }^{*} p<.05$

Tablo 8'e göre, “Her gün” İnternet kullanan öğrencilerin İnternet bağımlılık puan ortalamaları (X=57.88, SS=18.89) “Ayda Birkaç Defa" İnternet kullanan (X=30.75, SS=5.97) ve "Haftada Birkaç Defa" İnternet kullanan $(X=41.14, S S=14.24)$ öğrencilerin puan ortalamalarından istatistiksel olarak anlamlı düzeyde ( $\mathrm{p}<.05)$ yüksektir. Öğrencilerin kullanım amaçları ve İnternet bağımlılık puanları ile ilgili betimsel istatistikler Tablo 9'da sunulmuştur.

Tablo 9. Öğrencilerin Kullanım Amaçlarına Göre İnternet Bağımlılık Puanları

\begin{tabular}{llccc}
\hline & İnternet Kullanım & & & \\
& Amaçları & $\boldsymbol{N}$ & $\boldsymbol{X}$ & $\mathrm{SS}$ \\
\hline \multirow{3}{*}{ İnternet Bağımlılı̆̆ı } & Araştırma Bilgi Edinme & 44 & 36.36 & 9.71 \\
& Eğlence & 100 & 57.00 & 18.75 \\
& İletişim & 76 & 53.45 & 20.11 \\
\hline
\end{tabular}

Tablo 9'da görüldüğü gibi öğrencilerin 44'ü İnternet'i daha çok "Araştırma ve bilgi edinme" ( $X=36.36$, SS=9.71) amaciyla, 100'ü “Eğlence” ( $X=57.00$, SS=18.75) amaciyla ve 76'sı $(X=53.45, S S=20.11)$ “İletişim” amacıyla kullanmaktadır. Öğrencilerin İnternet bağımlılık seviyelerinin İnternet kullanım amaçlarına göre farklılaşıp farklılaşmadığı ANOVA ile incelenmiş ve sonuçlar Tablo 10' da sunulmuştur.

Tablo 10. Kullanım Amaçlarına Göre İnternet Bağımlılık Puanları ANOVA Sonuçları

\begin{tabular}{llllll}
\hline & $\begin{array}{l}\text { Kareler } \\
\text { Toplamı }\end{array}$ & sd & Kareler Ortalaması & F & $p$ \\
\hline Gruplar Arası & 14238.87 & 2 & 4776.29 & & \\
Gruplar İçi & 68825.48 & 217 & 318.64 & 14.89 & $.000^{*}$ \\
Toplam & 83064.35 & 219 & & & \\
${ }^{*} p<.05$ & & & &
\end{tabular}

Tablo 10 incelendiğinde lise öğrencilerinin İnternet bağımlılığı ölçeği puan ortalamalarının kullanım amaçları değişkenine göre farklılaştığı görülmektedir $[F(2,217)=14.89$, p<.05]. Farkın kaynağını 
belirlemek ve çoklu karşılaştırmalar yapmak amacıyla Scheffe testi uygulanmış ve sonuçlar Tablo 11'de sunulmuştur.

Tablo 11. Öğrencilerin Kullanım Sıklığına Göre İnternet Bağımlılık Seviyeleri Scheffe Testi

\begin{tabular}{|c|c|c|c|c|c|}
\hline & $\begin{array}{l}\text { İnternet Kullanım } \\
\text { Amaci }\end{array}$ & Karşılaştırmalar & $\begin{array}{l}\text { Ortalamalar } \\
\text { Fark1 }\end{array}$ & $S H$ & $p$ \\
\hline \multirow{6}{*}{$\begin{array}{l}\text { İnternet } \\
\text { Bağımlılık } \\
\text { Puanları }\end{array}$} & \multirow{2}{*}{ Araştırma Bilgi Edinme } & Eğlence & -20.64 & 3.24 & $.000^{*}$ \\
\hline & & İletişim & -17.08 & 3.39 & $.000^{*}$ \\
\hline & \multirow{2}{*}{ Eğlence } & Araştırma Bilgi Edinme & 20.64 & 3.24 & $.000^{*}$ \\
\hline & & İletişim & 3.55 & 2.72 & .429 \\
\hline & \multirow{2}{*}{ İletişim } & Araştırma Bilgi Edinme & 17.08 & 3.39 & $.000^{*}$ \\
\hline & & Eğlence & -3.55 & 2.72 & .429 \\
\hline
\end{tabular}

${ }^{*} p<.05$

Tablo 11'e göre, "Eğlence" amacıyla İnternet kullanan öğrencilerin İnternet bağımlılık puan ortalamaları ( $X=57.00, S S=18.75)$ ve "İletişim" amacıyla İnternet kullanan öğrencilerin İnternet bağımlılık puan ortalamaları ( $X=53.45$, SS=20.11), "Araştırma ve Bilgi Edinme" amaciyla İnternet kullanan öğrencilerin İnternet bağımlılık puan ortalamalarından $(X=36.36, S S=9.71)$ istatistiksel olarak anlamlı düzeyde $(\mathrm{p}<.05)$ yüksektir.

\section{Üçüncü Alt Probleme İlişkin Bulgular}

Öğrencilerin İnternet bağımlılık seviyelerinin genel akademik başarı ortalamaları ile ilişkisini incelemek amacıyla korelasyon analizi yapılmış ve sonuçlar Tablo 12' de sunulmuştur.

Tablo 12. Öğrencilerin İnternet Bağımlılık Seviyeleri ile Genel Akademik Başarıları İlişkisi

\begin{tabular}{|c|c|c|c|}
\hline Değişkenler & $N$ & $r$ & $p$ \\
\hline İnternet Bağımlılık Puanı & \multirow{2}{*}{220} & \multirow{2}{*}{.-345} & \multirow{2}{*}{$.000^{*}$} \\
\hline Akademik Başarı Ortalaması & & & \\
\hline
\end{tabular}

Tablo 12 incelendiğinde, Pearson Çarpım Moment Korelasyon analizi sonucuna göre puanlar arasında istatistiksel açıdan anlamlı düzeyde ( $\mathrm{p}<.05)$, negatif yönde $(\mathrm{r}=,-345)$ ve orta etki büyüklüğünde bir ilişki saptanmıştır.

Öğrencilerin İnternet bağımlılık seviyelerinin devamsızlık durumları ile ilişkisini incelemek amacıyla korelasyon analizi yapılmış ve sonuçlar Tablo $13^{\prime}$ te sunulmuştur.

Tablo 13. Öğrencilerin İnternet Bağımlılık Seviyeleri ile Devamsızlık Durumları İlişkisi

\begin{tabular}{lccc}
\hline Değişkenler & $N$ & $r$ & $p$ \\
\cline { 1 - 1 } İnternet Bağımlılık Puanı & 220 & .653 & $.000^{*}$ \\
\hline Devamsızlık Durumu & 220 & &
\end{tabular}

Tablo 13 incelendiğinde, gerçekleştirilen Pearson Çarpım Moment Korelasyon analizi sonucuna göre puanlar arasında istatistiksel açıdan anlamlı düzeyde $(p<.05)$, pozitif yönde $(r=653)$ ve orta etki büyüklügünde bir ilişki saptanmıştır. 


\section{Tartışma, Sonuç ve Öneriler}

Bulgulara göre araştırmaya katılan lise öğrencilerinin 79'u (\%36) “Bağımlı Değil”, 84'ü (\%38) “Muhtemel Bağımlı" ve 57'si (\%26) “İnternet Bağımlısı" profilindedir. Bu bulguya göre lise öğrencilerinin \%64'ünün İnternet bağımlısı veya bağımlılık risk grubunda olduğu söylenebilir. Hem ulusal hem de uluslararası alanyazında ergenlerde İnternet bağımlılığını konu edinen birçok çalışmaya rastlanmaktadır. Bu araştırmaların bulgularına göre ergenlerde İnternet bağımlılığı oranlarının düşük düzeyde (Lam, Peng, Mai ve Jing, 2009; Lin ve Tsai, 1999; Siomos, Dafouli, Braimiotis, Mouzas ve Angelopoulos, 2008), orta düzeyde (Deniz ve Gürültü, 2018; Gezgin, Cakir ve Yildirim, 2018; Neverkovich ve arkadaşları, 2018) ve yüksek düzeyde (Altundag ve Yucel, 2019; Al-Shdayfat, Hawi, Hamadneh, Albnian, Alzyoud \& Logue, 2016; Khan ve Awan, 2017) olduğu görülmektedir. Daha eski çalışmalarda İnternet bağımlılığı oranları düşük düzeyde iken güncel çalışmalarda bu oranın giderek yükseldiği görülmektedir. Mevcut çalışma bulguları da bu sonucu destekler niteliktedir. Ergenlerde İnternet bağımlılığı oranlarının yükselmesinin nedenlerinden birinin İnternet ve mobil cihazların kullanımının giderek yaygınlaşması olduğu düşünülmektedir.

Öğrencilerin İnternet bağımlılık seviyeleri ile cinsiyetleri ve ailelerinin sosyo-ekonomik durumları arasında istatistiksel olarak anlamlı farklılık bulunmamıştır. Alanyazında araştırma bulguları ile örtüşür çalışmalar yer almaktadır (Çelik, Çelen ve Seferoğlu, 2014; Lau, Gross, Wu, Cheng ve Lau, 2017). Bununla birlikte bazı çalışmalarda İnternet bağımlılığının cinsiyet ve sosyo-ekonomik durum değişkenlerine göre farklılık gösterdiği (Çavuş, Ayhan ve Tuncer, 2016; Kayrı ve Günüç, 2016; Wang, Wu ve Lau, 2016) belirtilmektedir. Mevcut araştırmada çalışma grubunda yer alan öğrencilerin benzer sosyo-ekonomik düzeylerde olduğu görülmektedir (\%84 orta düzey). Ayrıca cinsiyete göre değişmeksizin tüm öğrencilerin İnternet erişimine sahip olduğu bilinmektedir. Benzer sosyo-ekonomik düzeylerde olan ve İnternet erişimi bulunan öğrencilerin İnternet bağımlılık eğilimleri de benzer olabilir. Bu nedenle, mevcut çalışmada İnternet bağımlılığının cinsiyet ve sosyo-ekonomik durum değişkenlerine farklılaşmadığı düşünülmektedir.

Lise öğrencilerinin İnternet bağımlılık seviyeleri İnternet kullanım süreleri ve amaçlarına göre istatistiksel olarak anlamlı düzeyde farklılaşmaktadır. İnternet kullanım süresi çoğaldıkça bağımlılık riski yükselmektedir. Ayrıca İnternet'i daha çok eğlence ve iletişim amacıyla kullanan öğrenciler, araştırma ve bilgi edinme amacıyla kullanan öğrencilere göre daha yüksek bağımlılık riski taşımaktadırlar. Bu durumun, öğrencilerin oyun ve eğlence konusunda araştırma ve bilgi edinmeye göre bilgisayar başında daha fazla zaman geçirmelerinden kaynaklandığı düşünülmektedir. Alanyazında bu bulguyu destekler nitelikte İnternet kullanım süresinin ve oyun, eğlence amaçlı kullanmanın bağımlılığı tetiklediğine yönelik bulgulara rastlanmaktadır (Akhter, 2013; Esen ve Siyez, 2011; Spada, 2014). 
Lise öğrencilerinin İnternet bağımlılık seviyeleri ile genel akademik başarı ortalamaları arasında istatistiksel olarak anlamlı düzeyde ve negatif yönde bir ilişki saptanmıştır. Bu bulguya göre öğrencilerin İnternet bağımlılık seviyeleri yükseldikçe genel akademik başarılarının düştüğü söylenebilir. İnternet bağımlılık seviyesi yüksek olan bireylerin düşük olanlara göre bilgisayar ve İnternet başında daha fazla vakit geçirdiği bilinmektedir. İnternet başında daha fazla vakit geçiren öğrenciler ödevlerini aksatabilir, günlük rutinlerini atlayabilir ve sınavlara hazırlanmakta daha isteksiz olabilirler (Young, 1998). Bu durumun zamanla, İnternet bağımlılık eğilimi yüksek olan lise öğrencilerinin akademik başarılarını olumsuz etkilediği düşünülmektedir. Nitekim alanyazında mevcut bulguları destekler şekilde İnternet bağımlılığının öğrencilerin akademik başarılarını olumsuz etkilediğine yönelik çalışma bulgularına rastlanmaktadır (Akhter, 2013; İskender ve Akın, 2010; Stavropoulus, Alexandraki ve Motti-Stefanidi, 2013).

Lise öğrencilerinin İnternet bağımlılık seviyeleri ile okula devamsızlık durumları arasında istatistiksel olarak anlamlı düzeyde ve pozitif yönde bir ilişki saptanmıştır. Bu bulguya göre öğrencilerin İnternet bağımlılık seviyeleri yükseldikçe okula devamsızlıklarının arttığı söylenebilir. İnterneti daha çok ve özellikle çevrimiçi oyun amaçıı kullanan bireylerin uyku problemleri yaşadıkları ve bu nedenle günlük işlerini aksattıkları belirtilmektedir (Lam, 2014). Mevcut çalışmada öğrencilerin \%45'i İnternet'i oyun ve eğlence amaçlı kullandığını belirtmiştir. Geç saatlere kadar İnternet'te çevrimiçi oyunlar oynayan öğrenciler sabah erken kalkıp okula gitmekte zorlanabilirler. Bu durumun öğrencilerin günlük rutinlerini olumsuz etkilediği ve okula devamsızlıklarının artmasına neden olduğu düşünülmektedir. Shaffer, Hall ve Bilt (2000), bu bulguyu destekler nitelikte bilgisayar ve İnternet'i aşırı kullanımın öğrencilerin okula geç kalmalarına neden olduğunu belirtmiştir.

Çalışmanın bulguları ışı̆̆ında aşağıdaki öneriler yapılmıştır:

Lise öğrencilerinin büyük çoğunluğunun İnternet bağımlısı veya bağımlılık riski ile karşı karşıya oldukları bulgusundan hareketle, öğrencilerin bilgisayar ve İnternet'in zararları konusunda bilgilendirilmeleri önerilmektedir. Kariyer planlamasının en önemli dönemlerinde olan lise öğrencilerine yönelik güvenli ve verimli teknoloji ve İnternet kullanımı eğitimleri planlanması ve bu eğitimlerin titizlikle yürütülmesi faydalı olabilir.

Çalışma bulgularında, aşırı İnternet kullanımının öğrencilerin genel akademik başarılarının düşmesine ve okula devamsızlıklarının artmasına neden olduğu ortaya konmuştur. Okul yönetimlerinin ve okullardaki rehberlik servislerinin İnternet bağımlılığı eğilimi gösteren öğrencileri belirleyip, önleyici tedbirler almaları faydalı olabilir. .

Bu çalışma katılımcı grubu olarak Tokat ili Merkez ilçede bulunan bir devlet lisesi ile sınırlıdır. Benzer çalışmaların başka illerde, daha geniş katılımcı grupları ile hatta ulusal boyutta yürütülmesinin, genel İnternet bağımlılık profilinin oluşturulması bakımından faydalı olacağı düşünülmektedir. 
Böylelikle, TBMM tarafından da gündeme getirilen ve önemli bir problem olarak görülen ergenlerde İnternet bağımlılığı ile daha etkili mücadele edilebilir.

\section{Kaynaklar}

Adiele, I., \& Olatokun, W. (2014). Prevalence and determinants of İnternet addiction among adolescents. Computers in Human Behavior, 31, 100-110.

Akhter, N. (2013). Relationship between İnternet addiction and academic performance among university undergraduates. Educational Research and Reviews, 8(19), 1793-1796.

Al-Shdayfat, N., Hawi, N., Hamadneh, S., Albnian, F., Alzyoud, S., \& Logue, T. (2016). İnternet addiction among school adolescents in Northeastern Jordan. World J Med Sci, 13(4), 218-24.

Altundag, C. K., \& Yucel, A. S. (2019). Research on high school students' İnternet addiction levels in critical thinking disposition. New Trends and Issues Proceedings on Humanities and Social Sciences, 6(4), 62-66.

Arısoy, Ö. (2009). İnternet bağımlılı̆̆ı ve tedavisi. Psikiyatride Güncel Yaklaşımlar, 1, 55-67.

Aydın, B. (2005). Çocuk ve ergen gelişimi. Ankara: Nobel Yayın ve Dağıtım.

Batıgün, A. D., \& Kılıç, N. (2011). İnternet Bağımlılığı ile Kişilik Özellikleri, Sosyal Destek, Psikolojik Belirtiler ve Bazı Sosyo-Demografik Değişkenler Arasındaki İlişkiler. Turk Psikoloji Dergisi, 26(67).

Bayraktar, F. (2001). İnternet kullanımının ergen gelişimdeki rolü. Yayımlanmamış yüksek lisans tezi, Ege Üniversitesi, İzmir.

Bicen, H., \& Cavus, N. (2010). The most preferred social network sites by students. Procedia-Social and Behavioral Sciences, 2(2), 5864-5869.

Büyüköztürk, Ş. (2015). Sosyal bilimler için veri analizi el kitabı: İstatistik, araştırma deseni. SPSS uygulamaları ve yorum (Gözden geçirilmiş yirmi birinci baskı). Ankara: Pegem Yayıncllık.

Cao, B., \& Lin, W. Y. (2015). How do victims react to cyberbullying on social networking sites? The influence of previous cyberbullying victimization experiences. Computers in Human Behavior, 52, 458-465.

Ceyhan, A. A. ve Ceyhan, E. (2014). Problemli internet kullanım ölçeğinin ergenlerde geçerlik ve güvenilirlik çalışması. Bă̆ımlılık Dergisi, 15(2), 56-64.

Çavuş, S., Ayhan, B. ve Tuncer, M. (2016). Bilgisayar oyunları ve bağımlılık: Üniversite öğrencileri üzerine bir alan araştırması. İletişim Kuram ve Araştırma Dergisi, 2016(43), 265-289.

Çelen, F. K., Çelik, A. ve Seferoğlu, S. S. (2011). Çocukların İnternet kullanımları ve onları bekleyen çevrim-içi riskler. Akademik Bilişim, 2, 1-8.

Çelik, A., Çelen, F. K. ve Seferoğlu, S. S. (2014). Ortaokul öğrencilerinin İnternet bağımlılık düzeylerinin çeşitli değişkenler açısından incelenmesi. Akademik Bilişim, 14, 273-282. 
Değirmenci, O. (2002). Bilişim suçları. Yayımlanmamış Yüksek Lisans Tezi, Marmara Üniversitesi Sosyal Bilimler Enstitüsü, İstanbul.

Deniz, L. ve Gürültü, E. (2018). Lise öğrencilerinin sosyal medya bağımlılıkları. Kastamonu Eğitim Dergisi, 26(2), 355-367.

Egger, O., \& Rauterberg, M. (1996). Internet behaviour and addiction. Unpublished master's thesis, Work \& Organisational Psychology Unit (IfAP), Swiss Federal Institute of Technology (ETH), Zurih.

Ekşi, F. (2012). Narsistik kişilik özelliklerinin İnternet bağımlılı̆̆ı ve siber zorbalığı yordama düzeyinin yol analizi ile incelenmesi. Kuram ve Uygulamada Ĕ̆itim Bilimleri, 12(3), 1683-1706.

Ergin, A., Uzun, S. U. ve Bozkurt, A. İ. (2013). Tıp fakültesi öğrencilerinde İnternet bağımlılığı sıklığı ve etkileyen etmenler. Pamukkale Tip Dergisi, (3), 134-142.

Esen, E. ve Siyez, D. M. (2011). Ergenlerde İnternet bağımlılı̆̆ını yordayan psiko-sosyal değişkenlerin incelenmesi. Türk Psikolojik Danışma ve Rehberlik Dergisi, 4,127-138.

Fuat, N. (2013). Üniversite öğrencilerinin İnternet kullanım durumları ve saldırganlık düzeyleri arasındaki korelasyon: Gaü psikoloji ve rehberlik ve psikolojik danışmanlık bölümü öğrencilerinde İnternet kaynaklı tutum değişiklikleri. Iccmtd-2013, 392.

Gezgin, D. M., Cakir, O., \& Yildirim, S. (2018). The relationship between levels of nomophobia prevalence and İnternet addiction among high school students: The factors influencing nomophobia. International Journal of Research in Education and Science, 4(1), 215-225.

Griffiths, M. D. (1999). İnternet addiction: Fact or fiction? The Psychologist, 12(5), 246-250.

Gülbahar, Y., Kalelioğlu, F. ve Madran, O. (2010, Ağustos). Sosyal ağların eğitim amaçlı kullanımı. XV. Türkiye'de İnternet Konferansında sunulan bildiri, İstanbul Teknik Üniversitesi, İstanbul.

Günel, A., Turhal, Ç. Ü. ve İmal, N. (2011). İlköğretim öğrencileri arasında İnternet kullanımının incelenmesine yönelik anket çalışması. A ̆ğ ve Bilgi Güvenliği Sempozyumu, Ankara, Türkiye.

Günüç, S. ve Kayri, M. (2010). Türkiye'de İnternet bağımlılık profili ve İnternet bağımlılık ölçeğinin geliştirilmesi: Geçerlik-güvenirlik çalışması. Hacettepe Üniversitesi Ĕ̆gitim Fakültesi Dergisi, 39(39), $220-232$.

Işık, U. (2007). Medya bağımlılığı teorisi doğrultusunda İnternet kullanımının etkileri ve İnternet bağımlilığı. Yayımlanmamış Yüksek Lisans Tezi, Selçuk Üniversitesi Sosyal Bilimler Enstitüsü, Konya.

İskender, M., \& Akin, A. (2010). Social self-efficacy, academic locus of control, and İnternet addiction. Computers \& Education, 54(4), 1101-1106.

Karaca, M. (2007). İnternet gençliği: yeni bir gençlik tiplemesi denemesi. Humanities Sciences, 2(4), 419436.

Karaca, A. ve Beyaznar, B. (2010). İnternette müstehcenlik: Nerede başlar ve nerede biter? XII. Akademik Bilişim Konferansı Bildirileri, I, 63-71. Muğla. 
Karasar, N. (2000). Bilimsel araştırma yöntemi (10. Baskı). Ankara: Nobel.

Kayrı, M., \& Günüç, S. (2016). Yüksek ve düşük sosyoekonomik koşullara sahip öğrencilerin internet bağımlılığı açısından karşılaştırmalı olarak incelenmesi. The Turkish Journal on Addictions, 3(2), 165-183.

Khan, H. U., \& Awan, M. A. (2017). Possible factors affecting İnternet addiction: a case study of higher education students of Qatar. International Journal of Business Information Systems, 26(2), 261-276.

Kılıç, M. (2018). Öğrenmenin doğası. Ankara: Pegem Akademi.

Kim, S., \& Kim, R. (2002). A study of İnternet addiction: Status, causes, and remedies- focusing on the alienation factor. International Journal of Human Ecology , 3(1), 1-19.

Kurtaran, G.T. (2008). Internet bağımlılı̆̆ını yordayan değgşkenlerin incelenmesi. Yayımlanmamış Yüksek Lisans Tezi, Mersin Üniversitesi, Mersin, Türkiye.

Lam, L. T. (2014). Internet gaming addiction, problematic use of the İnternet, and sleep problems: A systematic review. Current Psychiatry Reports, 16(4), 444.

Lam, L. T., Peng, Z. W., Mai, J. C., \& Jing, J. (2009). Factors associated with İnternet addiction among adolescents. Cyberpsychology \& Behavior, 12(5), 551-555.

Lau, J. T., Gross, D. L., Wu, A. M., Cheng, K. M., \& Lau, M. M. (2017). Incidence and predictive factors of İnternet addiction among Chinese secondary school students in Hong Kong: A longitudinal study. Social Psychiatry and Psychiatric Epidemiology, 52(6), 657-667.

Lin, S. S., \& Tsai, C. C. (1999). İnternet addiction among high schoolers in Taiwan.

Mitchell, P. (2000). Internet addiction: Genuine diagnosis or not? The Lancet, 355(9204), 632.

Morsünbül, Ü. (2014). The association of İnternet addiction with attachment styles, personality traits, loneliness and life satisfaction. International Journal of Human Sciences, 11(1), 357-372.

Nalwa, K., \& Anand, A.P. (2003). İnternet addiction in students: A cause of concern. Cyberpsychology $\mathcal{E}$ Behavior, 6(6). 653-656.

Neverkovich, S. D., Bubnova, I. S., Kosarenko, N. N., Sakhieva, R. G., Sizova, Z. M., Zakharova, V. L., \& Sergeeva, M. G. (2018). Students' İnternet addiction: Study and prevention. Eurasia Journal of Mathematics, Science and Technology Education, 14(4), 1483-1495.

Niemz, K., Griffiths, M., \& Banyard, P. (2005). Prevalence of pathological İnternet use among university students and correlations with self-esteem, the General Health Questionnaire (GHQ), and disinhibition. CyberPsychology E Behavior, 8(6), 562-570.

Odabaşığlu, G., Öztürk, Ö., Eraslan, D., Genç, Y., Kalyoncu, Ö. ve Ayhan, Ö. (2007). On olguluk bir seri ile İnternet bağımlılı̆̆ klinik görünümleri. Bă̆ımlılık Dergisi, 8(1), 46-51.

Ofcom, (2008). Ofcom's Submission to the Byron Review. Office of Communications, London, UK. http://www.ofcom.org.uk/research/telecoms/reports/byron/. 
Özdemir, M. ve Akar, F. (2011). Lise öğrencilerinin siber-zorbalığa ilişkin görüşlerinin bazı değişkenler bakımından incelenmesi. Kuram ve Uygulamada Eğitim Yönetimi Dergisi, 17(4), 605-626.

Eisner, (2010). Is social media a new addiction? Retrevo Blog. http://www.retrevo.com/content/blog 2010/03/social-media-new-addiction\%3F.

Satan, A. A. (2013). Ortaöğretim öğrencilerinde akran baskısının İnternet bağımlılı̆̆ına olan etkisi. International Journal of Social Science, 6, 511-526.

Shaffer, H. J., Hall, M. N., \& Bilt, J. V. (2000). “Computer addiction”: a critical consideration. American Journal of Orthopsychiatry, 70(2), 162-168.

Shepherd, R. M., \& Edelmann, R. J. (2005). Reasons for İnternet use and social anxiety. Personality and individual Differences, 39(5), 949-958.

Siomos, K. E., Dafouli, E. D., Braimiotis, D. A., Mouzas, O. D., \& Angelopoulos, N. V. (2008). İnternet addiction among Greek adolescent students. CyberPsychology \& Behavior, 11(6), 653-657.

Spada, M. M. (2014). An overview of problematic İnternet use. Addictive Behaviors, 39(1), 3-6.

Stavropoulos, V., Alexandraki, K., \& Motti-Stefanidi, F. (2013). Recognizing İnternet addiction: prevalence and relationship to academic achievement in adolescents enrolled in urban and rural Greek high schools. Journal of Adolescence, 36(3), 565-576.

TBMM. (2012). Bilgi toplumu olma yolunda bilişim sektöründeki gelişmeler ile İnternet kullanımının başta çocuklar gençler ve aile yapısında olmak üzere sosyal etkilerinin araştırılması amacıyla kurulan meclis araştırma komisyonu raporu. Türkiye Büyük Millet Meclisi, Ankara. https://www.tbmm.gov.tr/develop/owa/genel kurul.cl getir?pEid=32275.

Turanalp, M. F. (2016). İnternetin ergenlere olumsuz etkileri üzerine din eğitimi temelli bir yaklaşım. Marife Dini Araştırmalar Dergisi, (1), 111-132.

TÜIK. (2018). Türkiyen'nin İnternet kullanım alışkanlıkları. Türkiye İstatistik Kurumu, Ankara. https://www.guvenliweb.org.tr/haber-detay/turkiyenin-İnternet-kullanim-aliskanliklari-tuik$\underline{2018 .}$

Waldron, H. B., \& Turner, C. W. (2008). Evidence-based psychosocial treatments for adolescent substance abuse. Journal of Clinical Child \& Adolescent Psychology, 37(1), 238-261.

Wang, Y., Wu, A. M., \& Lau, J. T. (2016). The health belief model and number of peers with İnternet addiction as inter-related factors of İnternet addiction among secondary school students in Hong Kong. BMC Public Health, 16(1), 272.

Ybarra, M. L. (2004). Linkages between depressive symptomatology and İnternet harassment among young regular İnternet users. CyberPsychology \& Behavior, 7(2), 247-257.

Young, K. (1998). İnternet addiction: The emergence of a new clinical disorder. Cyberpsychology $\mathcal{E}$ Behavior, 1 (3), 237-244. 
Young, K. S., \& Case, C. J. (2004). İnternet abuse in the workplace: new trends in risk management. CyberPsychology \& Behavior, 7(1), 105-111.

Yükselgün, Y. (2008). Illköğretim dördüncü ve beşinci sını öğrencilerinin İnternet kullanım durumlarına göre saldırganlık ve sosyal beceri düzeylerinin incelenmesi. Yayımlanmamış Yüksek Lisans Tezi, Eskişehir Osmangazi Üniversitesi, Eskişehir.

\section{ORCID}

Ŏguzhan Tekin ${ }^{1}$ https://orcid.org/0000-0002-6825-3309

\section{Extended Summary}

The Relationship between High School Students' Internet Addiction Levels with Their Grade Point

\section{Average and Absenteeism}

\section{Introduction}

In the world and Turkey computers, internet and mobile technology usage trends have been increasing steadily. According to Turkey Statistical Institute (TSI) data, household internet owner rates have been incrased year by year. While this rate was $18.9 \%$ in 2007 , increased to $83.4 \%$ in 2018 . For Turkey, being a developing country and having a high population of young and adolescent are thought to be significant in increasing usage of internet and mobile devices. Indeed, statistics show that, starting age to use internet in Turkey is nine and that it gradually decreases, and the highest usage rate by age groups is $15-24$ with $82 \%$. Internet brings many benefits for every field of human life. Internet, which is an effective communication and information sharing tool, facilitates business and daily life considerably. With opportunities offered by the internet, traditional communication methods that require large investments have changed and internet users have begun to share their knowledge and ideas easily and cost-effectively with the whole world. In addition to the convenience and benefits it offers, the problematic use of internet may cause serious problems such as the fact that its use is open to everyone without supervision, no information discrimination, excessive information load, information insecurity, and internet addiction. It can be said that internet and mobile technologies are the most accepted among children and adolescents in the society and these problems are mostly affect children and adolescents. Because, it is considered that children and adolescents who are weaker in terms of self-regulation and are more susceptible to external influences will be exposed to the harms of the internet as well as the benefits of it. Internet and mobile technologies are seen as a means of entertainment and leisure for children and adolescents. Previous research findings show that children and adolescents mostly use the internet to follow social media and play online games. At this point, two main problems are noteworthy. First, problems with time management and efficient use of time and the second and perhaps most important one is the problem of addiction that can occur due to too much time spent on the Internet. 
Internet addiction, which refers to a negative situation, is generally defined as to spend too long time on the internet and the inability to control the urge of using internet. According to researches, internet addiction has negative effects for individulas on business and academic performances, quality of sleep, social life and emotional stability. In addition, internet or technology addiction has been reported as a pathological and psychological disorder in the medical world. For example; It has been observed that children's and young people's cognitive processes are impaired, interpersonal sensitivity decreases and general health decreases. It was also determined that addicted persons' social development and selfconfidence decreased, social anxiety levels and aggression behaviors were increased. One of the most important reasons for increasing internet usage among children and adolescents is social networks such as Facebook, Twitter, Instagram because these social networks tend to increase their user accounts and develop continuously worldwide. When the time spent in these networks is not controlled, it is possible that it will have a negative impact on individuals and trigger addiction. High school students possible to face problems such as the confusion of identity experienced in the adolescence, the tendency to live in extreme dimensions, social adjustment dissorders, choice of profession and the tension caused by the high competition environment in the exams. High school students may use internet problematically as a strategy to deal with these and similar problems. It is known that internet addiction is seen as an important pathological disorder which adversely affects social and academic life of individuals by many researchers and psychologists. Considering that children and adolescents use internet and technology mostly, the possible addiction risk is higher for them.

\section{Purpose of the Study}

In current study, it is aimed to determine the internet addiction levels of high school students and to investigate the relationship between this level and students' grade point average and absenteeism. It is considered that it will be very useful to determine the internet usage habits and addiction levels of high school students. The findings of the study are expected to help bringing recommendations to school administrators and the school guidance service to take necessary precautions.

\section{Method}

The method of the current study designed for this purpose was a relational survey model based on the quantitative research paradigm. The study group of the research consisted of 220 ninth and tenth grade students selected with appropriate sample method in the central district of Tokat, Turkey in the Spring term of 2017-2018 academic year. The data of the study were collected with the "Internet Addiction Scale" and "Personel Information Form", and e-school system is used for to obtain students' general academic achievement and absenteeism data. In the analysis of the data descriptive statistics such as frequency, percentage and standart deviation were used for the internet addiction levels of students. In addition procedural statistics such as t-test for gender variable, ANOVA for internet usage 
time and purpose variables, and regression analize for the relationship between the internet addiction levels and grade point average and absenteeism were also performed. The significance level is taken as .05 in all measurements.

\section{Findings}

Findings of the study revealed that; $25.91 \%$ of the students were internet addicts, $38.18 \%$ were probable addicted and $34.91 \%$ were non-addicted. According to the findings, internet addiction levels of secondary school students did not show a statistically significant difference according to their gender. In addition, it was found that there was a significant negative correlation between internet addiction levels and general academic achievement averages and there was a significant positive correlation between internet addiction levels and absences. According to the research results; it can be said that a significant portion of high school students (64.09\%) participated in the study were at the limit of internet addiction or addictied and as the students' internet addiction levels increased, their overall academic achievement average decreased and their absences increased. 